\title{
Music Computer Technologies in Computer Science and Music Studies at Schools for Children with Deep Visual Impairment
}

\author{
Irina B. Gorbunova and Alexis M. Voronov
}

\begin{abstract}
The article analyzes the processes of information, transforming the environment of training of pupil with visual impairment. There is a necessity to change the content of the information education in connection with the use of specialized software, and hardware and digital educational resources. Special rehabilitation centers that teach computer science and contemporary information technology (IT) and allow student with visual impairment to adapt to the development and independent use of specialized IT, help in solving a number of important problems. The tiflotechnik class implements contemporary technological capabilities for training visually impaired information and music computer technologies. Analysis of the peculiarities of the use of music computer technologies (MCT) by rehabilitators with visual impairments shows that currently blind musicians have the opportunity to master a number of MCT-programs (sequencers, audio editors, etc.), which contributes to the most profound disclosure of their creative potential.

The development of IT and MCT offer unique opportunities for visually impaired students to provide and receive information almost in full. The authors of article describe the experience of working with students with deep visual impairment in the process of teaching them contemporary IT.
\end{abstract}

Keywords - computer science, creative activities, information technology, music computer technologies, visually impaired.

\section{INTRODUCTION}

It is believed that vision provides more than $80 \%$ of information about the outside world. The blind or visually impaired person is partially limited in the choice of the source of information. Most of these people do not have the opportunity to read books, newspapers, magazines and other flat-printed publications, navigate in space and move through streets without of an accompanying person's help. The development of information technologies (IT) opens up unique prospects for pupil with visual impairment (we are talking about more severe cases, although they include [2], [3]) to provide and receive information almost in full [10], [11]. With the use of specially

Irina B. Gorbunova. the Department of Information Technology, Institute of Computer Science and Technological Education of the Herzen State Pedagogical University of Russia and Educational and Methodological Laboratory Music Computer Technologies of the Herzen State Pedagogical University of Russia, St. Petersburg. Alex M. Voronov. the Department of Information Technology, Institute of Computer Science and Technological Education of the Herzen State Pedagogical University of Russia and Educational and Methodological Laboratory Music Computer Technologies of the Herzen State Pedagogical University of Russia, St. Petersburg. developed technologies, blind pupil are able to use such actions as creating, processing and editing electronic texts, reading flat-screen literature, printing materials from electronic formats in special Braille; maintaining various kinds of databases, communicating in social networks, as well as searching and placement of information on the Internet. All this gives the blind person the opportunity to get a profession corresponding to his/her interests [15], [17].

Special rehabilitation centers that teach music computer technologies (MCT) and contemporary IT and allow pupil with visual impairment to adapt to the development and independent use of specialized IT, help in solving a number of important problems.

\section{TifloteChNiC Class: TEACHING It AND MCT To STUDENTS WITH VISUAL IMPAIRMENT}

The workplace for the rehabilitant, who is trained according to the methodology developed by us, consists of the following components:

a soft computer chair, which has the ability to pick up the height so that it is convenient for those who have a small balance of vision to look at the monitor screen;

a two-tier computer desk where the student can place his/her hands for the convenience of free movement of the computer mouse, and, if necessary, the use of a Braille display for more accurate display and development of the information received;

the monitor screen diagonal of nineteen inches, set to the highest resolution and font magnification for people with residual vision;

on both sides of the monitor there are active speakers for playing audio files, as well as speech output using the system of voice assistants and the screen access programs; for sound playback, you can use headphones provided at each workplace;

a high-quality vocal microphone, which allows rehabilitants to record and process their own voice;

on the left of the table there is a special double-sided high-speed Braille printer for printing on double-format sheets (newspaper format). This device allows you to print out electronic texts in Braille, so that the rehabilitant could not only hear the information reproduced by the speech synthesizer, but also read it;

a scanning and reading machine, which provides the opportunity to make available to blind and visually impaired people a wide range of printed materials using the latest technology of optical character recognition of a scanned text 
which is read aloud in the chosen language and a user-defined voice, adjustable speed, volume, tone, listening material; it is also possible to conserve the informati on on digital media;

a television, which is designed to read digital talking books, recorded on flash cards in a specially designed format. The player contains electronic memory and electronic bookmarks, which makes it easy to find the desired fragment, continue playback from the desired episode and move through the text, adjusting the speed of speech playback;

a portable Braille display allows blind users to freely navigate the Windows operating system. All buttons can be individually customized to the needs of a particular user. The wheels allow you to scroll lines, sentences, paragraphs and entire documents. There is an additional way to navigate using the joystick or the rocker button. Using a combination of scroll buttons, rocker buttons, and curs or buttons, you can easily navigate through the body of a document of any format;

a stationary video magnifier, which allows visually impaired people to read books, magazines, recipes, it allows you to consider the small details of any object;

a GPS-device for blind and visually impaired users which is a compact device equipped with a navigator with voice control and designed to orient the blind and visually impaired student on the ground. Multi-transport navigation is carried out on foot or by car and you can find the road with the help of voice navigation; digital maps for exploring the area; getting real-time voice description of what surrounds you while walking; obtaining information about your location, etc.

In the class of tiflotechnic we provide a MIDI-keyboard for those who can realize their musical abilities; we have developed and implemented it in the educational process of the special program of teaching computer arrangements for people with impaired vision. The manuals have developed modules and classes aimed at providing opportunities for teaching computer musical creativity blind musicians using the "method of projects" $[6,12]$ on the basis of music computer technologies (MCT) [9], [12]. This has become possible thanks to the developments of scientists involved in solving the problems of computer modeling of the creative process, in particular, the modeling of the process of musical creativity and the use of its results in the system of contemporary music education [1], [4-7].

In addition to special equipment, there are also some speech programs (JAWS, NVDA, etc.) designed for voice access to the information displayed on the PC screen. This access is carried out by means of computer synthesis of a speech signal with its output on the sound-transmitting device. This allows the blind user to work with a wide range of programs for various purposes, using a text display mode, including text editors, table processors, programming systems, some educational games. (Read more about the possibilities of teplotehnich class analysis for teaching IT and MCT to students with visual impairment written in [13], [16].)

\section{The MaIN Modules Of It TRAINING For Visually IMPAIRED STUDENT}

The main modules of IT training for visually impaired student consist of the following thematic blocks:

1) Familiarity with the special equipment installed in the class of tiflotechnic, the main features and possibilities of its practical application.

2) The computer device and operating system. Computer capabilities for a person with visual impairment. It sets up the operating system for the correct operation of the voice assistant.

3) Work with a computer keyboard, the location of the keys and the main keyboard functions. Here we talk about the specific purpose of each key, what function it performs when working in the operating system, study the location of the keys on the number and letter rows. For those who want to learn how to type quickly, there are special keyboard simulators with voice prompts and special tasks for spell checking and error detection in fast printing.

4) Basic principles of work with programs of screen access ("voice assistants"), voicing the information displayed on the screen, which helps the blind or visually impaired person to freely navigate in the settings and commands of the operating system, to work with electronic, audio and video materials, to sound work on the Internet; system requirements and features that must be observed when using them.

5) Principles of operation of operating systems of the 'Windows' line (desktop, start menu and context menu, basic system keyboard commands required by the user when working on the computer, etc.).

6) What are "hot keys" and how they can help to make the work easier for the blind and visually impaired, not using a computer "mouse" in the work.

7) Working with files and folders using keyboard shortcuts, editing, filling and moving. Basic concepts about extensions and file types (audio, video, photos, etc.).

8) Work with data (information), transfer data to various removable media (flash drives, removable hard drives and $\mathrm{CDs}$ ). Working with data without using a mouse, there are system commands for such operations. Archiving the information, to configure the archiver. Basic combinations for saving and deleting information from the hard drive or removable media. Types of media for high-quality and reliable storage of information.

9) Working with dialogs and pop-up system messages, what to do when the system messages appear, when you need to minimize or expand the system window, what key combinations you can use to switch between Windows, and what is convenient for working with multiple tasks at the same time.

10) Work in popular text editors (word processors, keyboard combinations used for text formatting, creation and formation of tables, spell checking, correction of spelling and syntax errors, the main differences between editors of different years of release, archiving of documents and text files to save space on the hard drive and removable media.)

11) Scanning of books, documents and photos, translation of 
texts from paper to electronic versions, recognition of scanned flat-printed texts with the help of special programs to be able to reproduce them by speech synthesizers. Setting the speed of reading playback, choosing the voice tone, the best for the perception of electronic voice.

12) Work with a "talking" electronic library, creation of electronic bookmarks for the convenience of listening, finding and keeping the fragments of the work, the translation of electronic texts in audio format for readability, "pocket" computers, mobile phones, tablets and iPods.

13) Work with sound and music, listening to audio files, watching videos with the help of various programs of players. Practical work in popular audio editors, easy to use for the blind and visually impaired, digitization of rare unique recordings from magnetic tapes and other analog media, cleaning of noise and other extraneous sounds without loss of quality, conversion of audio and video materials, transfer from one format to another to save space on the hard disk and removable media.

14) Work with e-mail, check the e-mail address, sending and receiving e-mail using a special e-mail clients come with features e-mail. Main shortcuts that are used when sending and receiving e-mail attachments.

15) The principle of operation of the blind and visually impaired in the global Internet, with the help of voice assistants voice information is displayed on the screen, the main features of the search and download information from the Internet resources, "hot keys" to speed up the network and get quick access to the desired information, as well as the ability to quickly find the desired link.

16) Work in popular search engines, search for the desired information using speech synthesizers (voice assistants), the presence of key combinations to speed up the work and sort out the data. Search and exchange of information in the global network and data exchange systems, the process and features of data acquisition, setting up special and additional programs, voicing information about the received data, speed, ratings, percentage of reception and transmission of information.

17) Getting to know and work with social networks, posting personal information, searching for people by groups and interests, inviting them to participate and viewing the news feed. Work in networks that support not only e-mail, but also voice communication, such as ICQ, Skype, etc., features and principles of blind and visually impaired people in voice chat. Setting up a special program that alerts the actions taking place on the monitor screen to carry out simultaneous communication in voice and electronic chats, which greatly increases the productivity of information.

18) Methods of self-posting information to the global network, viewing information and, if necessary, save it to your computer, the main keyboard commands that help to navigate the work with the data.

19) Familiarity with the thematic discussion of the Internet mailing for blind and visually impaired users, subscription, registration and direct participation in special electronic forums on interests.
20) Possibility to work with modern touch displays, control icons with the help of specially provided gestures for the blind and visually impaired. Access to information through the voice assistant, which is provided on touch tablets.

The method of teaching IT to visually impaired pupil involves doing homework after each lesson, so that students can analyze, consolidate and test the material in a real-life situation, and, in case of ambiguities, ask the appropriate questions.

\section{CONCLUSION}

The problem of teaching a blind student and a student with deep visual impairment contemporary IT lies also in the fact that the contingent is heterogeneous according to the type of existing visual pathologies, by type of visual impairment (total blindness or porcelina), at the time of the occurrence of the defect: blindness is congenital or acquired and so on. The number of hours of the rehabilitant's presence is determined depending on the need and level of his/her initial information training, as well as his/her health.

At the same time, each group of the blind, united on the basis of the severity of visual pathology, is characterized by the presence of certain psychological features that the teacher of information and communication technologies must bear in mind [13], [16]. Knowledge of these features will help to competently and accurately represent the training material necessary for the study of a group of rehabilitators.

Analysis of the peculiarities of the use of MCT by people with visual impairments shows that currently blind musicians have the opportunity to master a number of MCT programs (sequencers, audio editors, etc.), which contributes to the most profound disclosure of their creative potential.

Special rehabilitation centers that teach computer and contemporary IT and allow pupil with visual impairment to adapt to the development and independent use of specialized IT, help in solving a number of important problems.

\section{REFERENCES}

[1] Belov, G.G., Gorbunova, I.B. Music and Cybernetics. Music and Time, 11, pp. 25-32 (2016).

[2] J.A. Borgesa, D. Tomé, "Teaching Music to Blind Children: New Strategies for Teaching through Interactive Use of Musibraille Software. Procedia Computer Science, 27, pp. 19- 27 (2014 ). https://doi.org/10.1016/j.procs.2014.02.004.

[3] Brauner D. Music Technology for the Visually Impaired (2017). online at http://www.perkinselearning.org/technology/posts/music-technology-vis ually-impaired

[4] Chibirev, S.V., Gorbunova, I.B. Modeling of Musical Creativity Process with the Use of Music Computer Technologies. Proceedings of Irkutsk State Technical University, 4 (75), pp. 16-24 (2013).

[5] Gorbunova, I.B. Computer Science and Computer Music Technologies in Education. Theory and Practice of Social Development, 12, pp. 428- 432 (2015).

[6] Gorbunova, I.B. Information Technology in Music and Music Education. The World of Science, Culture, Education, vol. 63, No. 2, pp. 206-210 (2017).

[7] Gorbunova, I.B. Music Computer: Modeling the Process of Musical Creativity, The World of Science, Culture, Education, 4 (65), pp. 145-148 (2017).

[8] Gorbunova, I.B. Music Computer Technologies and Digital Humanities. Contemporary Music Education-2015, Proceedings of the XIV International Scientific and Practical Conference, vol. 1, pp. 29-34. 
Publishing house "The Herzen State Pedagogical University of Russia", St. Petersburg (2015).

[9] Gorbunova, I.B. Musical-Computer Technology: the Laboratory. Mediamusic. [Online], $\quad 1, \quad$ pp. $\quad 5-7 \quad$ (2012). http://mediamusic-journal.com/Issues/1_5.html.

[10] Gorbunova, I.B. New Artistic Worlds. Interview with Irina B. Gorbunova, Professor of the Herzen State Pedagogical University of Russia. Music in School, 4, pp. 11-14 (2010).

[11] Gorbunova, I.B. The Epoch of Information Technology in the Music and Creative Space. Materials of the 12th St. Petersburg International Conference "Regional Informatics-2010", St. Petersburg, pp. 232-233 (2010).

[12] Gorbunova, I.B. The Phenomenon of Music Computer Technologies as New Creative Educational Environment. Izvestia: Herzen University Journal of Humanities and Sciences, 4 (9), pp. 123-138 (2004).

[13] Gorbunova, I.B., Govorova, A.A., Music Computer Technologies as a Means of Teaching People with Visual Impairment Musical Art. Theory and Practice of Social Development, 11, pp. 298-301 (2015).

[14] Gorbunova, I.B., Romanenko, L.Yu., \& Rodionov, P.D. Music Computer Technologies in Formation of Information Competence of the Contemporary Musician, Scientific-technical Bulletin of Saint-Petersburg State Polytechnic University. Humanities and Social Sciences, 1 (167), pp. 39-48 (2013).

[15] Gorbunova, I.B., Voronov, A.M. Music Computer Technologies in Teaching the Computer Science for Visually-Impairment Students at Higher Musical Schools. Contemporary Musical Education-2010: Proceedings of the VIII International Scientific and Practical Conference, pp. 287-290, Publishing house "LEMA", St. Petersburg (2011).

[16] Govorova, A. A., Voronov, A.M. Musical-Computer Technologies in Inclusive Education for People with Disabilities of Health Impaired: Analysis of the Existing Problems and Prospects of Use. The World of Science, Culture, Education, 2 (63), pp. 210-212 (2017).

[17] Voronov, A.M., Gorbunova, I.B., Kameris, A. \& Romanenko, L.Yu., Music Computer Technologies in the Digital Age School. Proceedings of Irkutsk State Technical University, 5 (76), pp. 256-261 (2013).

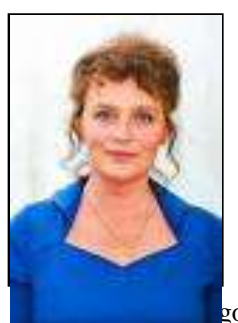

Irina B. Gorbunova was born in Saint Petersburg (Leningrad). DipMus, Special Music Higher School of the St. Petersburg State Conservatory named after N.A. Rimsky-Korsakov; BSc in Computer Science: Information Technology, Computer Science and Multimedia, Leningrad State University, Ussurisk State Pedagogical University; MA in Education, the Herzen State Pedagogical University of Russia; $\mathrm{PhD}$ in Information Technology and Pedagogic Sciences, the ogical University of Russia, St. Petersburg, 1989; Doctor degree: Doctor of Pedagogic Sciences and Information Technology, the Herzen State Pedagogical University of Russia, St. Petersburg, 1999. Dr. Gorbunova, Full Professor, PhD in Sc., Doctor of Pedagogic Sciences, Chief Researcher of the Educational and Methodological Laboratory Music Computer Technologies of the Herzen State Pedagogical University of Russia, St. Petersburg.

She was on a number of business trips abroad, among them working trip to the USA (1999); lecturing and giving research and practice seminars in Hungury (2003, 2005, 2017); business trip to the UK (2016); she was a member of the Jury of national and international competitions of musical creativity, including Bridge of Friendship (Dortmund, Germany, 2011), etc. Work experience; 1990 - 2010 - Associate Professor, Professor of the Department of Information Technology of the Herzen State Pedagogical University of Russia, St. Petersburg; 2010 - present - Full Professor of the Department of Information Technology, Institute of Computer Science and Technological Education of the Herzen State Pedagogical University of Russia, St. Petersburg; 2002 - present - Chief Researcher of the Educational and Methodological Laboratory Music Computer Technologies of the Herzen State Pedagogical University of Russia, St. Petersburg. She has more than 300 scientific publications, among them are monographs Music Computer Technologies: Historical-Theoretical and Practical Aspects, St. Petersburg: Publ. house "SMIO Press" (2007, 560 pp.) and Music Computer Technologies: The Problem of Modeling the Process of Musical Creativity, compiled with participation of S. V. Chibirev , St. Petersburg: Publ. house of the Herzen State Pedagogical University of Russia (2012, 160 pp.); course book Information
Technology in Music, vol. 1 - 4: vol. 1, Architectonics of musical sound (2009, 175 pp.), vol. 2, Musical Synthesizers (2010, 205 pp.), vol. 3, Music Computer (2011, 411 pp.), Music, Mathematics and Computer Science, vol. 4, compiled with participation of Mikhail S. Zalivadny (2013, 181 pp.), St. Petersburg: Publ. house of the Herzen State Pedagogical University of Russia. Her research activities include such directions as: MCT in professional music education (as a means to expand creative opportunities); MCT in general musical education (as one of the means of education); MCT as a means of rehabilitation of people with disabilities; MCT as the new direction in preparation of specialists of humanitarian and technological profile; MCT in the field of digital arts; MCT in information technology, psychoacoustics and musical acoustics; system of training arrangements and the art of performing skills on electronic musical instruments. Her circle of interests also includes the problems of interrelation of natural and technical sciences and humanities, as well as the possibilities of applying the results of such interrelation for the purposes of music education and upbringing. She also takes part in working out the specialized software for computer music devices and in application of this software in pedagogical processes. Her developments and researches also belong to the field of musical pedagogics and musicology, musical Informatics, computer modeling of processes of musical creativity, timbre programming, art of performing skills and arrangement on electronic musical instruments, creative work in the field of computer music, mathematical methods in musicology.

Prof. Dr. Gorbunova is Chairman of the Organizing Committee of the international research and practice conference Contemporary Music Education, Chairman of the Organizing Committee of the international research and practical conference Music Computer Technologies in the System of Contemporary Education. Dr. Gorbunova is a member of the Jury of national and international competitions of musical creative works, including Electronic Palette (Saint-Petersburg), Music and Electronics (Moscow), Music of the XXI Century (Moscow / Saint-Petersburg), International Festivals and Competitions Musical Electronics and Multimedia (Moscow I Saint-Petersburg), Clarine of the XXI Century (Saint-Petersburg), The World of Art without Borders (Saint-Petersburg, Russia - Szeged, Hungary), Bridge of Friendship (Dortmund, Germany), All-Russian Competition of Electroacoustic Music DEMO (Saint-Petersburg). She is a member of Editorial Boards of International Journals: Music Scholarship / Problemy Muzykal'noj Nauki (SCOPUS), The World of Science, Culture, Education / Mir Nauki, Kul'tury, Obrazovaniya, Electronic international scientific journal of music and sound in electronic mass media, film, Internet, and multimedia MEDIAMUSIC. Prof. Dr. Gorbunova has developed first ever course in Music, called Music Computer Technologies, which has been offered under the Bachelors of Arts and Sciences (BASc), , which in 2004 carried out student recruitment in different regions and educational institutions of Russia and she also leads post-graduate courses "Music Computer Technologies in Education" available under the MA in Music Education, since 2006. Prof. Dr. Gorbunova supervises a number of doctoral and post-doctoral students (more than 30 ) and lectures on Music Computer Technologies and Information Technology in Music. She supervises research in various directions, among them there are: Theory and history of culture, Music Art, Information system and processes, Theory and methodology of professional education, Mathematical modelling, numerical methods and program systems, Theory and methods of education and upbringing (in Music, Informatics, natural sciences). The research results of Prof. Gorbunova were published in over 300 refereed publications including 48 books and 255 papers in journals and conference proceedings. Awards and honors: 2003 - Gold medal of the all-Russian Exhibition Centre (former VDNKh); 2005 - Silver medal of the all-Russian Exhibition Centre (former VDNKh); 2009 - Gold medal of the all-Russian Exhibition Centre (former VDNKh); 2009 - Diploma of the winner in the nomination «New educational technologies in ICT environment» of the all-Russian creative contest of scientific-technical solutions, educational products and services in the field of Informatization of the innovative-educational complex «Music computer technologies in the system of modern education»; 2010 - Grand Prix of International Congress-exhibition «Global Education - Education Without Borders»; 2010 - Diploma of the 11th all-Russian forum «Educational environment - 2010» for the project «Digital educational resources «Music computer technologies in education» in nomination of «Creative Competition of scientific developments, innovative solutions and programs in the field of higher vocational education» and many others; 2011 - Laureate of the Prize of the Government «For Outstanding Achievements in the Field of Higher and Secondary Professional Education»; 2013 - Honorary Worker of Higher Professional Education of the Russian Federation. 